Характеризуя большевизм, Степун определяет его как чисто русское явление, неразрывно связанное как c «географической бескрайностью», так и с «психологической безмерностью» России. Степун видит истоки большевизма как в русской ментальности, так и в философском мировоззрении Толстого и Достоевского. Бердяев почти так же представлял себе сущность большевизма, который был основан на чуждом для России марксизме.

Степуну выпала возможность непосредственно поработать с народным комиссаром просвещения Луначарским, который был вежлив в обращении с сотрудниками и позволял себя критиковать. Более того, советский министр, в отличие от немецкого министра Геббельса, не давил на личность подчиненных. Степун обратил внимание и на то, что в речах и беседах наркома проявлялась большая, чем у других советских чиновников, терпимость к людям и «разносторонняя начитанность». В то же время Степун подмечал, что «толерантность и мягкость» Луначарского никоим образом не распространялись на его поведение в политических делах. Кроме того, Степун видел, как Луначарский не любил вести и игнорировал хозяйственные дела (в том числе несвоевременно начислял жалование сотрудникам).

Степуну пришлось столкнуться со знаменитым режиссером Мейерхольдом, представителем Наркомпросса, который обличал «реакционную идеологию и эклектически-упадочный репертуар» театра Федора Августовича. По мнению философа, Мейерхольд, являясь представителем футуризма и стремясь в своем творчестве отразить марксистскую идеологию и создать новаторский театр, поспособствовал закрытию мешавшего ему театра Степуна.

УДК 165.19

Науч. спец. 09.00.01

DOI: 10.36809/2309-9380-2019-24-53-56

\section{СПЕЦИФИКА РАЦИОНАЛЬНО- АНАЛИТИЧЕСКОГО УРОВНЯ СТАНОВЛЕНИЯ КАРТИНЫ СОЦИАЛЬНО- ИСТОРИЧЕСКОЙ РЕАЛЬНОСТИ}

В статье рассматривается проблема формирования картины социально-исторической реальности с позиций детерминации парадигмальными установками стиля мышления субъекта. Становление картины социальной истории осуществляется в установках культурно-познавательной системы. Субъективность стиля мышления предстает в виде концептуальных проектов отражения истории.

Ключевые слова: рациональность, наука, стиль мышления, субъективность.
Свое отношение к большевизму, марксизму и ленинизму Степун хорошо выразил на допросах в ЧК, назвав большевизм «тяжелым заболеванием народной души», а российский марксизм-ленинизм - лживой верой, отвлекшей народ от веры в Бога и построения свободолюбивого социалистического общества. Более того, Федор Августович предвидел, что советская власть превратит смертную казнь в нормальный способ управления страной.

Высылка Степуна из России вместе с другими известными философами и яркими представителями отечественной культуры лучше всего подтверждает его философские идеи о сущности большевизма и ленинизма и объясняет, почему в нашем государстве установился со временем тоталитарный режим Сталина.

1. Степун Ф. А. Соч. М. : Российская политическая энциклопедия (РОССПЭН), 2000. 1000 с.

2. Степун Ф. А. Бывшее и несбывшееся / послесл. Р. Гергеля. 2-е изд., испр. СПб. : Алетейя, 2000. 651 с.

3. Бердяев Н. А. Малое собр. соч. СПб. : Азбука, АзбукаАттикус, 2016. 672 с.

4. Коган Л. А. «Выслать за границу безжалостно» (Новое об изгнании духовной элиты) // Вопр. философиии. 1993. № 9. С. $61-84$.

5. Гусляров Е. Что потеряла Россия 95 лет назад, выслав за границу образованных, мыслящих, талантливых «контрреволюционеров» // Родина. 2017. № 9. https:// biblionika.info/knizhnyy-dozor/dozor-cgb/3070-zhurnal-rodina9-2017.html (дата обращения 10.09.2019).

(C) Пинчук В. Н., 2019

\title{
SPECIFICITY OF RATIONAL-ANALYTICAL LEVEL OF THE PATTERN FORMATION OF SOCIO-HISTORICAL REALITY
}

The article deals with the problem of forming a pattern of socio-historical reality from the standpoint of its determination by the paradigmatic settings of the thinking style of the subject. The formation of the pattern of social history is carried out within the framework of the cultural and cognitive system. The subjectivity of the style of thinking appears in the form of conceptual projects of reflection of history.

Keywords: rationality, science, style of thinking, subjectivity.

В любой сфрере деятельности - созидание картины социально-исторической реальности не является в этом смысле исключением - на определенном этапе развития возникают задачи по осмыслению механизмов формирования нового знания, определению их познавательной значимости и оценке достигнутых результатов. В предельно 
общем смысле реализация эвристического потенциала предполагает способность субъекта конструировать идеальную перспективу познавательной активности в соответствии с системой свойств, определяющих онтологический статус исторического явления в рамках комплекса актуальных приоритетов. Главная особенность познания заключается в том, что оно реализуется не как проявление врожденных биологических способностей и инстинктов субъекта, а в качестве целенаправленной переработки результатов достижений общественно-исторического опыта в контексте социальной адаптации человека. При этом субъект не только усваивает устоявшиеся парадигмы познания, но и в соответствии с требованиями эффективности вносит рационально обоснованные изменения в систему познавательной активности. Развитие мышления может идти только не путем овладения специальными навыками и умениями в разных областях знания, но и путем развития способности к мыслительной деятельности как таковой [1, с. 159].

Рациональность представляет собой совокупность общественно выработанных интеллектуальных операций, направленных на преодоление дисгармонии целей и средств их достижения. Обнаружение нового составляет основную задачу научной рефлексии как в аспекте отражения внешних свойств реальности, так и в контексте определения сущности. В самом общем виде мышление и есть познание, так как в своей сущности ориентировано не на практическое, а на познавательное отношение к действительности: в процессе мышления происходит идеальная реконструкция объекта в совокупности его внешних и внутренних свойств. Рациональное мышление не только составляет систему категориально-понятийного выражения информации, полученной системой конкретно-чувственного уровня (аккумулирующего сущностные представления), но и выступает критерием его объективности с позиций общепринятых принципов.

В истории гносеологии классическая рациональность определяется как всеобъемлющая логико-эмпирическая обусловленность мышления. Рациональным признавалось только то, что не противоречит данным опытного знания, обоснованной теории и правилам логики. Подобное понимание рациональности оставляет за границами своего внимания проблему культурно-исторической обусловленности и знания, и организации системы его получения. Всеобщие формы рефлексии, которым подчинена деятельность субъекта, созидающего картину социально-исторической реальности, определяют его с позиций внешних по отношению к нему факторов, с которыми он вынужден считаться не менее, чем с качествами непосредственного объекта исследования. «...Культура, отделенный от меня "образ жизни” становятся моим неустранимым окружением...» [2, с. 113]. Субъект находится под детерминирующим влиянием сложившихся форм организации знания, которые не образуются им самим, а принимаются в процессе его собственной социализации. «...Каждый отдельный человек учится быть человеком. Чтобы жить в обществе, ему недостаточно того, что ему дает природа при его рождении. Он должен еще овладеть тем, что было достигнуто в процессе исторического развития человеческого общества» [3, с. 11].
Включение в систему понимания специфики становления образа истории, знания, обретенного до начала целенаправленного освоения объекта исследования (предзнания), открывает возможности обнаружения связей рационального уровня рефлексии с культурно-историческим комплексом детерминации познавательной системы в целом. Существование предзнания заставляет признать, что правила развития познания в контексте научной рациональности определяются в том числе и знанием, изначально присутствующим в сознании субъекта. На этом уровне содержатся исходные идеи, определяющие базовые черты образа реальности и комплекс гносеологических установок ее организации. Это своеобразные паттерны, которые, воздействуя на систему организации рационального стиля мышления, в совокупности с накопленным научным опытом однозначно детерминируют теоретический уровень рефлексии.

Принимая готовое знание, выступающее в роли предзнания, субъект сталкивается не только с действительностью в ее конкретно-практическом значении, но и с идеализированной действительностью, определяемой через общепризнанную систему логических форм, упорядоченных в комплексе концептуальной теории. «Общественно-человеческое освоение действительности совершается непосредственно, через усвоение всеобщих понятий и категорий. И именно через усвоение знания индивид усваивает всеобщее (общественное) значение вещей, или, другими словами, вещи в их непосредственно всеобщем значении» [4, с. 149]. Научная теория определяет реальность в форме абстрактной всеобщности, выраженной посредством системы логических форм, через которые она, преодолевая конкретно-практическую ограниченность, становится реальностью мышления.

Особенностью такого положения дел оказывается то, что объект мыслительной деятельности позиционируется как объективное явление, а мыслительное действие, не выделяясь в самостоятельное звено, осуществляется как объективное преобразование. «Создается самовоспроизводящая информационная структура - репликатор, выполняющий функцию создавать "более или менее точные свои копии... конкурируя с другими репликаторами в борьбе за материальный ресурс репликации"» [5, с. 149]. Подобное положение дел конструирует ситуацию тождества сущности системы познания и законов мышления, последнее как высший продукт деятельности головного мозга человека выступает в роли основного фактора познания, создания новых идей, их анализа и оценки. «Поскольку значительная часть исторической информации относится к... стереотипам мышления... то они составляют важный и непреходящий предмет исследования» [6, с. 16]. Объект, преобразованный в идеальную форму, существует не как элемент объективной действительности, а как элемент существующей системы знаний в рамках идеальной, связанной с материей, но не материальной схемы действительности.

Всеобщие принципы правильного мышления, позволяющие получать адекватные поставленным задачам результаты, выступают по отношению к познавательной потенции индивида в качестве объективной действительности, т. е. внешней по отношению к познавательным ресурсам субъекта. Эти принципы не являются результатом активности 
индивидуального интеллекта, отражением действительности в сознании отдельного субъекта, они формируются только в системе общественной культуры и обуславливают систему познавательной активности индивида. При этом необходимо учитывать, что реальным носителем познавательной активности является субъект, который непосредственно осуществляет построение картины социально-исторической реальности. «Мышление невозможно оторвать от "Я" - в этом уже заложена предпосылка трансцендентальной философии, как она впоследствии была развита Кантом» [7, с. 113]. Познанием на уровне восприятия непосредственной жизни занимается субъект - индивид, поэтому в ряд первоочередных проблем выдвигаются вопросы, связанные с активностью субъекта. «Очевидно, что познание и мышление как его основной инструмент возникают во взаимодействии человека с окружающей его действительностью и являются одной из наиболее сложных форм этого взаимодействия в головах отдельных людей, обладающих определенными способностями, потребностями, мотивами, эмоциями» $[1$, с. 7$]$.

Обращаясь к процессу исторической ресрлексии, мы констатируем, что он представляет собой оперирование санкционированной обществом системой категорий и принципов, однако их применение всегда индивидуально, что и составляет решающий момент идеаторности. Парадигма мышления выступает для субъекта в качестве абсолютного условия организации познания, требующего усвоения и соответствия принципам усвоенного. Рациональность это не только способность к идеаторной активности, но и оформление ее результатов в понятные для других формы. Предметом познания здесь выступают логические формы, в которых мышление осуществляет обработку чувственной информации. Изменение ракурса рассмотрения проблем влечет за собой постановку новых вопросов, которые, в свою очередь, заставляют субъекта формировать новую систему их решения, для чего необходимо внести изменение в предыдущую парадигму исследования. Прямым следствием такого положения дел является возникновение новых видов исторической картины мира: истории экономики, отдельных территорий, гендерной истории, истории идей. Эта возможность обусловлена, с одной стороны, системой отношений субъекта и объекта познания, с другой - способностями субъекта перестраивать комплекс взаимодействия субъекта с объектом в зависимости от изменения познавательной парадигмы. Данные обстоятельства обуславливают систему мыслительной активности, придавая ей специфический избирательный и, следовательно, неполный, ограниченный характер в контексте ориентировочно-исследовательской определенности, включая анализ имеющейся и вновь поступающей информации, выделение существенных и несущественных, известных и неизвестных условий решаемой проблемы.

Картина реальности, получаемая нами в процессе восприятия, отфильтрована определенным ментально-гносеологическим комплексом (стилем мышления). Прибегая к определенной системе рефлексии, мышление выявляет свойства, существующие объективно, но в рамках заданной парадигмы оно выделяет те свойства и связи объекта, которые этой же парадигмой и были актуализированы.
«В актуализации как реальном явлении, с которым сталкиваются исследователи, поражает то, что припоминаемое знание всегда оказывается соответствующим задаче, что припоминается не все, а лишь нужное для решения» [1, с. 162]. Актуализация - это не приложение имеющегося багажа знаний к решению определенных проблем, это особый механизм мышления, реализуемый субъектом в целях освоения нового в условиях решения конкретной задачи. «Весь ход решения задачи - это, по существу, открытие заново теоремы, формулировка которой появляется только в конце. Оказывается, что почти каждый шаг решения подводит к тем отношениям, связям, элементам, которые содержатся в теореме. Этот процесс можно сравнить с воссозданием полной картины внешнего облика какого-нибудь древнего, вымершего... невиданного животного, которую исследователь составляет по размерам зубов, костей скелета, некоторым возможным пропорциям различных частей тела. Каждая из этих находок не позволяет определить ее место в системе целого. Но несколько элементов и, главное, несколько соотношений важнейших элементов дают "внезапно" это новое целое» [1, с. 163]. Мышление предстает как специальный инструмент, направленный на раскрытие свойств исследуемого объекта путем включения его в определенную систему отношений, в рамках которых раскрываются возможности превращения неизвестного в свою противоположность - известное. Любая логическая модель содержит момент определенного допущения, это обусловлено фактом многослойности исторической реальности. Допущение является обязательным условием познания и в этом смысле не препятствует получению действительного знания об исследуемом объекте, так как позволяет реконструировать систему сущностных отношений организации объекта в определенных его состояниях. Правомерность подобного подхода можно проиллюстрировать на системах формально-логической и диалектико-логической парадигм мышления.

Законы и общие правила традиционной логики могут быть применены для изучения истории как отражения отношений обособленных и противопоставленных друг другу исторических комплексов, в таком ракурсе в рамках формальной логики возможно отражение только конкретных аспектов исторического явления. Диалектическая логика претендует на способность к выражению бытия и действия всеобщих законов его организации в развитии. При этом законы диалектической логики не отвергают формальнологические законы, а включают их в систему конструирования картины социально-исторической реальности как средство, позволяющее эффективно отражать моменты ее целостности. Эта возможность обусловлена, с одной стороны, системой отношений субъекта и объекта познания, с другой стороны, способностями субъекта перестраивать комплекс взаимодействия с объектом в зависимости от изменения познавательной парадигмы. Данные обстоятельства обуславливают систему мыслительной активности, придавая ей специфический избирательный и, следовательно, неполный, ограниченный характер в контексте ориентировочно-исследовательской определенности, включая анализ имеющейся и вновь поступающей информации, выделение существенных и несущественных, известных и неизвестных условий решаемой проблемы. 
Ориентировочно-исследовательская деятельность приводит к формулированию новых условий, на основе которых создаются предпосылки решения проблемной ситуации, выделяются ресурсы, которые с максимальной степенью вероятности приведут к решению исследовательской задачи. Способ решения проблемы зависит от наличия у субъекта исторической рефлексии необходимых установок на отражение содержания и объема объектно-предметной сферы исторической реальности. «Если знания добываются в процессе мышления, то и процесс мышления, в свою очередь, предполагает уже наличие какого-то знания; если мыслительный акт приводит к новому знанию, то какието знания, в свою очередь, всегда служат опорной точкой для мышления» [3, с. 22]. Данные процессы протекают на неосознанном уровне, превращаются в интеллектуальные навыки, составляющие основу автоматизированного мышления, вследствие чего и субъект не в состоянии объяснить решение задачи и сформулировать принципы решения. «Логические конструкции имеют тенденцию к отрыву от реальности, функционированию по своим собственным закономерностям, элиминирующим закономерности объективной реальности» [8, с. 93].

Таким образом, рациональное отражение истории осуществляется посредством вычленения из содержания исторического явления определенных свойств, установления актуальных связей между ними, перехода от частных, случайных, внешних связей к закономерным, существенным, всеобщим принципам. Способность субъекта устанавливать по отношению к объекту определенную позицию проявляется в качестве инвариантов рационально-логического стиля освоения исторического. При этом очевидно, что отражение исследуемого явления в логических формах может рассматриваться только как бесконечный процесс приближения субъекта к объекту, знания к истине. Ресурсы достижения знания о свойствах и качествах объекта (исторического события), полученного в процессе практической реализации ресурсов мышления, состоят в формализации его уникальных особенностей. В этом процессе неформализованное знание всегда будет нуждаться в определенном

УДК 130.122

Науч. спец. 09.00.13

DOI: 10.36809/2309-9380-2019-24-56-58

\section{ФИЛОСОФСКО-АНТРОПОЛОГИЧЕСКОЕ ОСМЫСЛЕНИЕ ДУХОВНЫХ ПРАКТИК}

В статье анализируются взгляды на природу и сущность духовных практик как уникального феномена человеческой культуры. Теоретический обзор, представленный автором, позволяет говорить о наличии разнонаправленных теоретических, методологических и праксеологических подходов к изучению духовных практик, которые существуют в рамках философии культуры.

Ключевые слова: духовные практики, духовность, нравственность, измененные состояния сознания. уровне формализации и, как следствие, всегда будет нести в себе отпечаток приблизительности соответствия реальности в рамках определенной ее модели. Так, одно и то же рационально-логическое выражение позволяет постигать явления различных уровней реальности не только потому, что эти явления объективно имеют определенную степень общности (материальное единство мира), но и в силу формализации их свойств в контексте определенной системы понятий и сложившейся системы их взаимодействия. Данное обстоятельство указывает на ограниченность рационального стиля мышления как универсального эвристического метода организации картины социально-исторической реальности, подчеркивая непосредственную зависимость от социальных условий его возникновения, развития и реализации.

1. Славская К. А. Мысль в действии (Психология мышления). М. : Политиздат, 1967. 208 с.

2. Библер В. С. Мышление как творчество (Введение в логику мысленного диалога) М. : Политиздат, 1975. 399 c.

3. Цветкова Л. С. Мозг и интеллект: нарушение и восстановление интеллектуальной деятельности. М. : Изд-во Моск. психол.-соц. ин-та, 2008. 424 с.

4. Ильенков Э. В. Философия и культура. М. : Изд-во Моск. психол.-соц. ин-та, 2010. 808 с.

5. Николаева Е. М. Социализация личности: синергетический дискурс (опыт социально-философского исследования). Казань : Изд-во КГУ, 2005. 176 с.

6. Хвостова К. В., Финн В. К. Проблемы исторического познания в свете современных междисциплинарных исследований. М. : Рос. гос. гуманит. ун-т, 1997. 256 с.

7. Гайденко Я. Я. История новоевропейской философии в ее связи с наукой. М. : ПЕР СЭ ; СПб. : Университетская книга, 2000. 456 c.

8. Брагин А. В. Мир как система и Человек. Иваново : Иван. гос. энергет. ун-т им. В. И. Ленина, 2001. 160 с.

(C) Степанов А. Г., 2019

\section{PHILOSOPHICAL-ANTROPOLOGICAL INTERPRETATION OF SPIRITUAL PRACTICES}

The article analyses philosophical and anthropological views on the nature and essence of spiritual practices as a unique phenomenon of human culture. The analytical review presented by the author allows us to talk about the presence of multidirectional theoretical, methodological and praxeological approaches to the study of spiritual practices that exist within the framework of the philosophy of culture.

Keywords: spiritual practices, spirituality, morality, altered states of consciousness. 